\title{
A Study on Evaluation of Various Tongue Patterns in North Indian Population and a Working Classification System for These Tongue Print Patterns
}

INTRODUCTION: Tongue is a vital internal organ enclosed within the oral cavity and is well protected from the external environment. The color, shape, and surface features are characteristic of every individual, and this serves as a tool for identification. The search for a new personal identification method secure has led to the use of the tongue print as a method of biometric verification.

AIM AND OBJECTIVE: To analyze the shape, margins, texture of tongue prints and compare these between males and females. Also, formulate a working classification system for these tongue prints.

MATERIAL AND METHODS: Subjects were asked to protrude tongue in relaxed position. After this tongue images were captured using Nikon digital camera to evaluate the shape, texture, margins, and papillations of tongue patterns.

RESULT: The most common pattern seen in males and females was Patternless, with majority of subjects showing scalloped lateral margins, prominent papillations with short and broad tongue. Mostly female patients had pointed tip of tongue. Also, we in this paper have formulated a working classification system for easily categorizing the tongue print patterns in individuals.

CONCLUSION: The human tongue is unique and delivers relevant information about shape, size, color, texture, margins and is suitable for forensic case identification.

KEYWORDS: Tongue Print, Forensic Identification, Classification, Vital Organ, Lesion

\section{INTRODUCTION}

Tongue is a vital organ which performs multiple actions such as articulation of speech, perception of taste, and formation of food bolus. ${ }^{1}$ The tongue is the only internal organ which can be easily drawn out and displayed for inspection and palpation purposes. ${ }^{2}$ By means of its shape and texture, its aspect and color analyzed in a particular moment, this organ is helpful due to its exposed portion comprising information with visible differences from one individual to another, and may be easily called and used as a "lingual impression". ${ }^{3}$

The individual lingual shape is consistent and the physiological texture is invariable. The human tongue is encased within the oral cavity, where it lies isolated from and protected against the external environment, just as the palatine folds do, unlike the other notorious elements employed in human identification. ${ }^{4}$ Hence, we, in this original study are describing the varied tongue patterns emphasizing the uniqueness of tongue. Also we have included certain morphological features for assessment like tongue size, shape, color, texture, margins and tip which has not been mentioned in the literature so far. Considering these criterias, we have formulated a simple working classification system of tongue patterns.

\begin{abstract}
AIM AND OBJECTIVE
1. To analyze the shape and texture of tongue.

2. To analyze the papillation on dorsal surface of tongue

3. To analyze the margins of the tongue.

4. To compare the shape, texture, papillation and margins of tongue between males and females.

5. To formulate a working classification of the tongue print patterns according to the above mentioned features.
\end{abstract}

\section{MATERIAL AND METHODS}

The study comprised of healthy individuals ( 15 males and 15 females).

\section{Inclusion criteria:}

a. Individuals in age group of 18-45 years were included.

b. Individuals free from any systemic disease.

c. Individuals without any tongue pathology.

d. Individuals without history of prior surgery that has caused deformity.

\section{Exclusion criteria:}

a. Individuals suffering from contagious diseases were excluded.

b. Individuals suffering from systemic diseases like 
hyperthyroidism, gigantism, dwarfism, syphilis, Down syndrome, post-mortem cases etc were excluded from the study.

c. Individuals with tongue deformity were excluded.

The tongue examination was carried following cleaning with sterile gauze and rinsing of oral cavity. Subjects were asked to protrude out tongue in relaxed position avoiding lingual muscle contraction. After this tongue images were captured using Nikon digital camera to evaluate the morphological aspects of dorsum of tongue like texture of tongue, shape of tongue, size of tongue, tongue margins, tip of tongue and papillations on tongue surface.

\section{RESULT AND OBSERVATION}

The most common pattern seen in males was patternless branching followed by $\mathrm{v}$ shaped fissures. Geographic tongue print pattern was noted in four male subjects. The most common pattern seen in females was patternless branching followed by vertical fissures and $\mathrm{v}$ shaped fissures. Also, five males and four females had scalloped tongue margins. Seven female and six male subjects had prominent papillations on dorsal surface of tongue.

Nine female subjects had broad and short tongue and six female subjects had narrow and long tongue. 10 male subjects had broad and short tongue and five had long and narrow tongue. Also, another feature observed was in female subjects who had pointed tip of tongue. Three male and four female subjects had plaqued tongue texture. Also one female subject had cleft tongue but not syndrome associated. Five male and three female subjects had comparatively large tongue. Another observation noted in female subjects was pointed tip of tongue compared to blunt tip of male subjects.

\section{DISCUSSION}

The morphology and the texture of tongue provide important information associated with oral hygiene of patient and/or any disease. 5 The exceptionality of the tongue is presented by the examination of shape, size, texture, margins, tip and color revealing visible differences between individuals, hence, making it a useful tool in forensic identification. ${ }^{6}$

The tongue has associated skeletal muscles, blood and nerve supply with papilla and taste buds. Simple visual comparison can indicate clear differences between normal and diseased condition. ${ }^{4}$
Based upon the characteristic morphological features and patterns of tongue, We have formulated a Working Classification of Tongue pattern as mentioned:

\section{Working classification system of tongue pattern:}

1. Size of tongue: Small and Large [Figure 1]

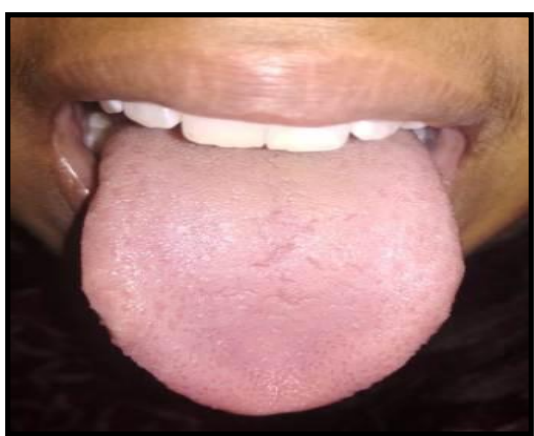

Figure 1. Photograph Reveals Large Size of Tongue

2. Shape of tongue: Long and Broad, long and narrow, short and broad, short and narrow [Figure $2 \mathrm{a} \& \mathrm{~b}]$

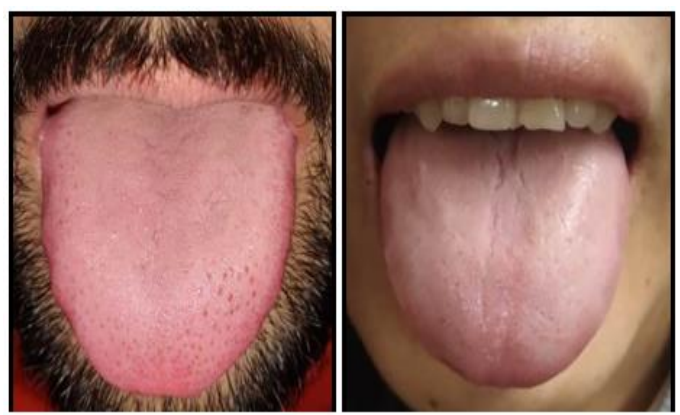

Figure 2 (a). Photograph Reveals Large and Broad Tongue and Figure 2 (b). Short and Broad tongue

3. Color of tongue: Pale, Pink, Reddish, Whitish, Brown, Pigmented [Figure 3]

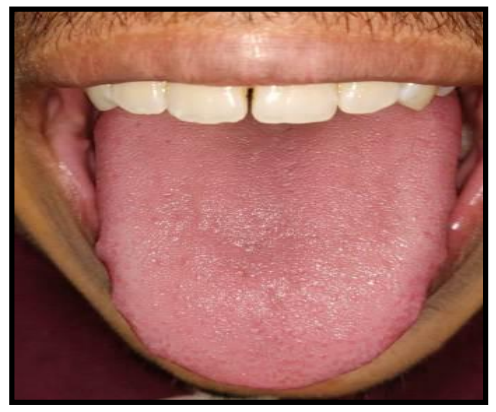

Figure 3. Photograph Reveals Normal Pink Color of Tongue 
4. Texture of tongue: Smooth, Rough, Ulcerated, Hairy, Edematous, Nodular [Figure 4]

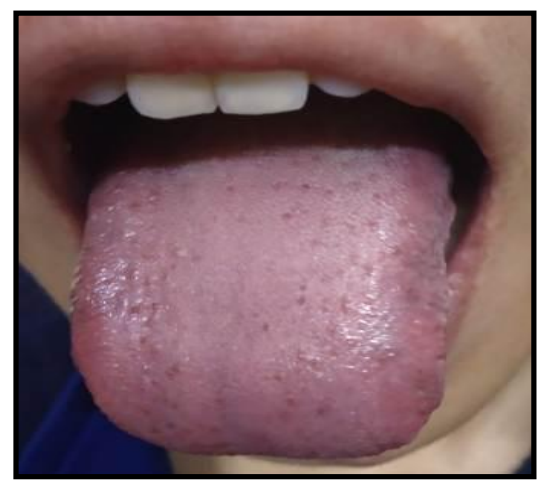

Figure 4. Photograph Shows Smooth Texture with Fungiform Tongue Papilla

5. Pattern on tongue surface: 1 . Fissured: V shaped, Coated tongue 2. Branched: Horizontal, Vertical, Patternless 3. Cleft, 4. Geographic pattern, 5. Hairy tongue [Figure $5 \mathrm{a} \& \mathrm{~b}$ ]
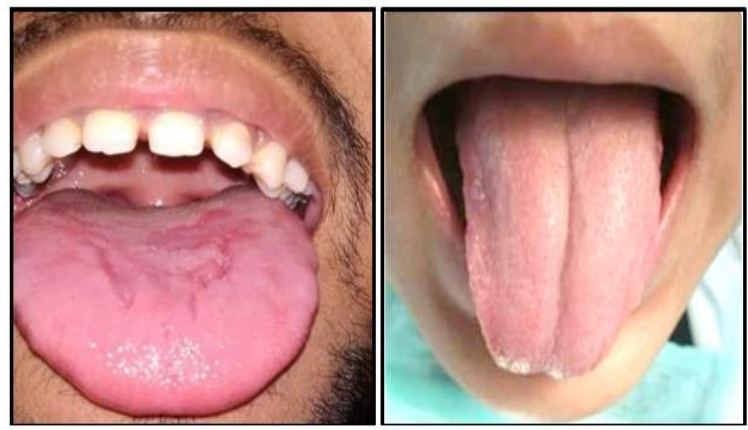

Figure 5 (a). Photograph Reveals Large and Broad Tongue and Figure 5 (b). Short and Broad tongue

6. Margins of tongue: Smooth, Scalloped, Ulcerated, Nodular [Figure 6]

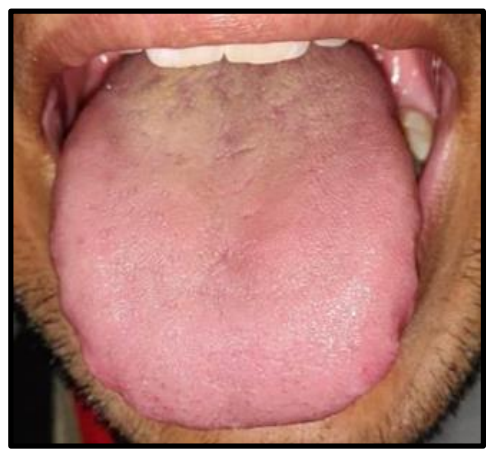

Figure 6. Photograph Reveals Scalloped Tongue Margins
7. Tip of tongue: Pointed (V shaped), Blunt (U shaped) [Figure 7]

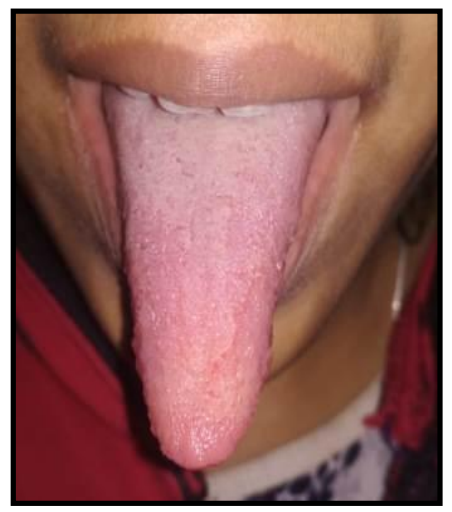

Figure 7. Photograph Reveals Pointed Tip of Tongue

According to Stefansu et al. geographic tongue pattern is typical feature seen in females compared to males but this did not correlate with present study. In our study, male subjects presented with geographic tongue. ${ }^{7}$ Also, scrotal/cleft tongue is a common feature of females which was similar to our study. ${ }^{7}$ Also, few subjects had coated tongue with fissures. Another finding in present case study consistent with previous studies is the tip of tongue which is pointed and $\mathrm{V}$ shaped in females predominantly.

Certain criteria were incorporated in our study that have not been mentioned in previous literature includes margin of tongue, color of tongue, texture of tongue.

The dorsal tongue surface is unique to individual as depicted by present study. Tongue print pattern are a useful tool in forensic study and can be used along with rugoscopy and lip prints for individual identification. ${ }^{8}$

To the best of our knowledge, the present study is unique as no such study has been conducted previously explaining the various tongue pattern with a working classification system of tongue patterns. ${ }^{9}$

\section{CONCLUSION}

Forensic odontology analyzes dental evidence in the concern of justice. The data obtained can help in identifying individual and providing relevant information for legal proceeding. The human tongue is unique and delivers relevant information about shape, size, color, texture, margins and is suitable for forensic case identification. It can be examined simply, making 
it valid evidence without hereditary dependence as no two individuals have identical tongue print patterns.

\section{REFERENCES}

1. Stefanescu CL, Popa MF, Candea LS (2014) Preliminary study on the tongue-based forensic identification. Rom J Leg Med 22:263-6.

2. Zhi Liu, Jing-Qi Yan, David Zhang, Qun-Lin Tang (2007) A tongue-print image database for recognition. Proceedings of the Sixth International Conference on Machine Learning and Cybernetics: Hong Kong, 19-22. v. 4, p. $2235-8$.

3. Radhika T, Jeddy N, Nithya S. Tongue prints: A novel biometric and potential forensic tool. J Forensic Dent Sci 2016;8:117-9.

4. Anastasi JK, Currie LM, Kim GH. Understanding diagnostic rea $\neg$ soning in TCM practice: Tongue diagnosis. Altern Ther Health Med 2009;15:18-28.

5. Zuo W, Wang K, Zhang D, Zhang H. Combination of polar edge detection and active contour model for automated tongue segmentation. Proceedings of Third International Conference of Image and Graphics; 2004:270-3.
6. Naaz R. Tongue biometric and its application in public use system. $3^{\text {rd }}$ international conference on machine learning and computing.

7. Diwakar M, Maharshi M. An extraction and recognition of tongue-print images for biometrics authentication system. Int J Comput Appl 2013;61:36-42. 8. Nagalaxmi V, Ugrappa S, Naga Jyothi M, Ch L, Maloth KN, Kodangal S. Cheiloscopy, palatoscopy and odontometrics in sex prediction and dis-crimination A comparative study. Open Dent J. 2015;8:269-79.
Source of support: Nil, Conflict of interest: None declared
Cite this article as:

Vijay P, Sharma S, Chandra S, Pardhe N, Singh P, Srivastava Y. A Study on Evaluation of Various

Tongue Patterns in North Indian Population and a Working Classification System for These

Tongue Print Patterns. Int Healthc Res J. 2019;3(2):76-79. doi: 10.26440/IHRJ/0302.05.521081

\section{$\underline{\text { AUTHOR AFFILIATIONS: }}$}

1. *Senior Resident, Department of Oral Pathology and Microbiology, KGMU, Lucknow (Corresponding Author)

2. Professor and Head, Department of Oral Pathology and Microbiology, KGMU, Lucknow

3. Professor and Head, Department of Oral Pathology and Microbiology, NIMS Dental College, Jaipur

4. Assistant Professor, Department of Oral Pathology and Microbiology, KGMU, Lucknow

5. $3^{\text {rd }}$ Year BDS undergraduate student, Faculty of Dental Sciences, KGMU, Lucknow

For article enquiry/author contact details, e-mail at: editor.ihrj@gmail.com,editor@ihrjournal.com 